DOI: 10.14526/2070-4798-2019-14-3-10-16

\title{
The influence of weight and hight parameters on the competition reliability of female single figure skaters in performing jump elements
}

\author{
Ivan V. Martynenko ${ }^{1}$, Ekaterina S. Borisenkova ${ }^{2 *}$ \\ ${ }^{1}$ Russian State University of Physical Education, Sport, Youth and Tourism \\ Moscow, Russia \\ ORCID: 0000-0oo1-5604-0763,w0102w@yandex.ru \\ ${ }^{2}$ Ural State University of Physical Education \\ Chelyabinsk, Russia \\ ORCID: 0000-0002-7318-9508, ekboris24@mail.ru*
}

\begin{abstract}
The article highlights some development trends in women's single figure skating: mastering and stable performance of ultra-c elements at international competitions. It shows competition reliability principles of athletes, as well as their dependence on the characteristics of the sport. Materials. The publication provides graphical demonstration of the study results regarding the influence of weight and height parameters of the world's elite female single figure skaters on their competition reliability in jumps' performance. Research methods. Analysis and synthesis of scientific literature, study of video materials and protocols of official starts, analysis of performances in the pre-Olympic season 2016-2017. Results. It is noted that absolute values of height and weight do not have an impact on stability of multi-turn jumps' performance. Only body mass index, showing the degree of fit between an individual's weight and height, affects the reliability of multi-turn jumps' performance. The results are obtained from the analysis of video materials and protocols of the official competitions. In addition, the article presents basic performance requirements of multi-turn jumps in competition programs for female single figure skaters. Skating architectonics and expressive components of the competition program are considered. Conclusion. The results of the research prove that success at official competitions depends on many factors, including the quality and quantity of complex jumps performed, as well as their location in a certain part of the skating program.

Keywords: figure skating, women's single skating, competition reliability, jump elements, ultra-c elements, weight and height parameters.
\end{abstract}

For citation: Ivan V. Martynenko, Ekaterina S. Borisenkova*. The influence of weight and hight parameters on the competition reliability of female single figure skaters in performing jump elements. Russian Journal of Physical Education and Sport. 2019, 14(3): 10-16. DOI: 10.14526/2070-4798-2019-14-3-10-16.

\section{INTRODUCTION}

Figure skating is a popular phenomenon in modern society. This is confirmed by the successful performance of Russian athletes in the international arena (in particular, in women's single skating); by the increased number of sports schools even in remote regions, as well as the number of their students and involved coaches; by the organization of large-scale entertainment events at various levels; by the substantial attention of media to this subject, etc. Only the components of figure skating: musicality, artistry, plasticity and increasingly complex movements' technique that promote the involvement of more and more people in this field - remain unchanged from the moment of its formalization into the distinct type of sports activity (since 1892) up to now.

Clear trends ensuring the development of this technical and aesthetic kind of sport can be found in modern women's single figure skating. With respect to jumps, women's single skating is inferior to men's in terms of the number of ultra-c elements in the form of a 3.5-rotation axel and quadruple jumps, which are still performed very rarely and only by few female figure skaters. However, women have recently reached a greater stability compared to many men in performing triple jumps and complex cascades. In addition, female figure skaters have been approbating quadruple jumps at Russian national competitions.

As the study showed, it is the weight and height characteristics of female athletes that have a significant impact on the reliability of jump elements performance in the framework of competition programs. The highest reliability is achieved by the athletes of medium height with a small weight. Overweight leads to frequent errors in jumps. Tall female athletes also find it harder to perform jumps, but their reliability is high enough if there is a good initial basis of jump technique $[1 ; 2]$.

In order to manage effectively the training process, coaches and athletes adhere to the standard 
indicators proposed by T. V. Skuratova, A. K.

Tikhomirov, V. L. Tikhomirova [3].

Table 1 - Average values of weight and height characteristics by age (T. V. Skuratova, A. K. Tikhomirov, B. L. Tikhomirova, 1983)

\begin{tabular}{|c|c|c|c|c|}
\hline \multirow{2}{*}{ Age, years } & \multirow{2}{*}{ Group } & \multicolumn{3}{|c|}{ Single skating } \\
\hline & & Weight, kg & Height, cm & Index, $\mathrm{kg} / \mathrm{m} 2$ \\
\hline 7 & $\mathrm{D}$ & 20,6 & 121,7 & 1,391 \\
\hline 8 & $\mathrm{D}$ & 26,2 & 127,4 & 1,614 \\
\hline 9 & $\mathrm{D}$ & 27,4 & 130,3 & 1,614 \\
\hline 10 & $\mathrm{D}$ & 30,0 & 135,9 & 1,624 \\
\hline 11 & $\mathrm{D}$ & 32,2 & 139,7 & 1,648 \\
\hline 12 & $\mathrm{D}$ & 34,5 & 144,0 & 1,664 \\
\hline 13 & $\mathrm{D}$ & 36,0 & 152,0 & 1,555 \\
\hline 14 & $\mathrm{D}$ & 38,0 & 155,0 & 1,582 \\
\hline 15 & $\mathrm{D}$ & 42,8 & 157,0 & 1,704 \\
\hline 16 & $\mathrm{D}$ & 45,0 & 162,0 & 1,715 \\
\hline 17 & $\mathrm{D}$ & 48,0 & 164,0 & 1,784 \\
\hline 18 and older & $\mathrm{D}$ & 50,0 & 165,0 & 1,836 \\
\hline
\end{tabular}

As it is fairly pointed out by Yu. Ya. Kiselev, the specificity of competition reliability is determined by the need for impeccable performance at the tournaments of a certain level with a given effectiveness in competitive sports environment during the entire competition [4].

Yu. I. Smirnov and I. I. Zulaev in their publication formulated the following principles of competition reliability theory [5]:

- the higher the competition potential of an athlete with respect to the obstructing factors, the greater the likelihood of achieving the intended sports result;

- the higher the planned sports result, the lower the likelihood of achieving it.

However, it is worth noting that the choice of indicators used for describing and ensuring athletic reliability is determined by the nature of athletes' competition functions, their complexity and specificity of competition requirements of a particular kind of sport [6].

When performing at competitions female single skaters need to demonstrate the expressiveness of the program. It is provided by the functional capacity, the advantageous location of the elements on the ice rink and in the temporal context, the impeccable technique, high complexity of the elements, focusing on individual characteristics and creating a complete image.

The architectonics of skating in this case is represented as follows: elements - connections - parts - composition. The first link of this chain includes steps, turns, spirals and binding components. In addition, the most difficult elements in this part are multi-turn jumps and spins. It is worth noting that the entire construct that complies with the canons of competition activity should not violate the artistic concept.

Competition program for adult women includes the following types of multi-turn jumps [7]:

- double or triple axel;

- one triple jump, which is preceded by connecting steps and/or similar movements of free skating;

- one cascade of jumps, consisting of double and triple or two triple jumps. A cascade of jumps may consist of two identical or different double or triple jumps. Jumps included in the cascade must be different from solo jumps.

Free program for adult women includes a maximum of seven jump elements (one of which must be an axel type jump). A separate jump can have any number of rotations. Cascades can be made up of the same and different single, double, triple and quadruple jumps, but there should be no more than three cascades in the program. One cascade of jumps can include three jumps, the other two can include two jumps.

\section{MATERIALS AND METHODS}

The representatives of women's single figure skating were identified during the organized study of the influence of weight and height parameters on the competition reliability of female single skaters in the process of performing jump elements. Based on the results of the 2017 World Championships, the following female skaters who took places on the podium were chosen as the study participants: E. Medvedeva, K. Osmond, G. Daleman.

In the process of collecting data from all the 
competitions, in which the athletes participated during the pre-Olympic season, it was found that, on average, the skaters performed in 14-16 programs (7-8 competitions). Video materials of short and free programs, as well as final protocols of the competitions were studied. All attention was paid to multi-turn jumps: technically well performed jumps, as well as jumps with errors, were revealed. Further, the reliability of jumps' performance at each competition of the 2016-2017 season was calculated for each female figure skater, after which the average reliability for the entire competition season was computed.

The reliability of jumps' performance was determined according the following formula:

$\mathrm{N}=$ Tperf. $/$ Tplan.$\times 100 \%$,

where $\mathrm{N}$ is the indicator of the reliability of jumps' performance (\%);

Tperf. - total coordination complexity of jumps performed in a technically correct way (in standard units);

Tplan. - total coordination complexity of all planned jumps (in standard units).

Body mass index (Adolphe Quetelet index) was calculated based on the available data on the height and weight of the athletes. Further, a diagram that showed the effect of body mass index on the reliability of multi-turn jumps' performance was drawn up.

\section{RESULTS AND DISCUSSION}

Based on the analysis of E. Medvedeva's performances, the following data presented in Table 2 and picture 1 was obtained.

Table 2 - Calculation of the reliability of jumps' performance by E. Medvedeva at the tournaments of the season 2016-2017

\begin{tabular}{|c|c|c|c|}
\hline Tournament & Tperf., standard units & Tplan., standard units & N, \% \\
\hline Japan Open 2016 & 73 & 73 & 100 \\
\hline $\begin{array}{c}\text { Skate Canada } \\
\text { International 2016 }\end{array}$ & 96 & 102 & 94,12 \\
\hline $\begin{array}{c}\text { Trophée Eric Bompard } \\
\text { 2016 }\end{array}$ & 94 & 102 & 92.16 \\
\hline $\begin{array}{c}\text { Grand Prix of Figure } \\
\text { Skating Final 2016 }\end{array}$ & 94 & 102 & 92.16 \\
\hline $\begin{array}{c}\text { Russian } \\
\text { Championships2017 }\end{array}$ & 102 & 102 & 100 \\
\hline $\begin{array}{c}\text { European } \\
\text { Championships 2017 }\end{array}$ & 102 & 102 & 100 \\
\hline $\begin{array}{c}\text { World championships } \\
\text { 2017 }\end{array}$ & 102 & 102 & 100 \\
\hline $\begin{array}{c}\text { World Team Trophy } \\
2017\end{array}$ & 102 & 102 & 100 \\
\hline
\end{tabular}

Figure 1 in the form of a diagram shows the dynamics of reliability of execution of multi-turn jumps in the season 2016-2017 E. Medvedeva.

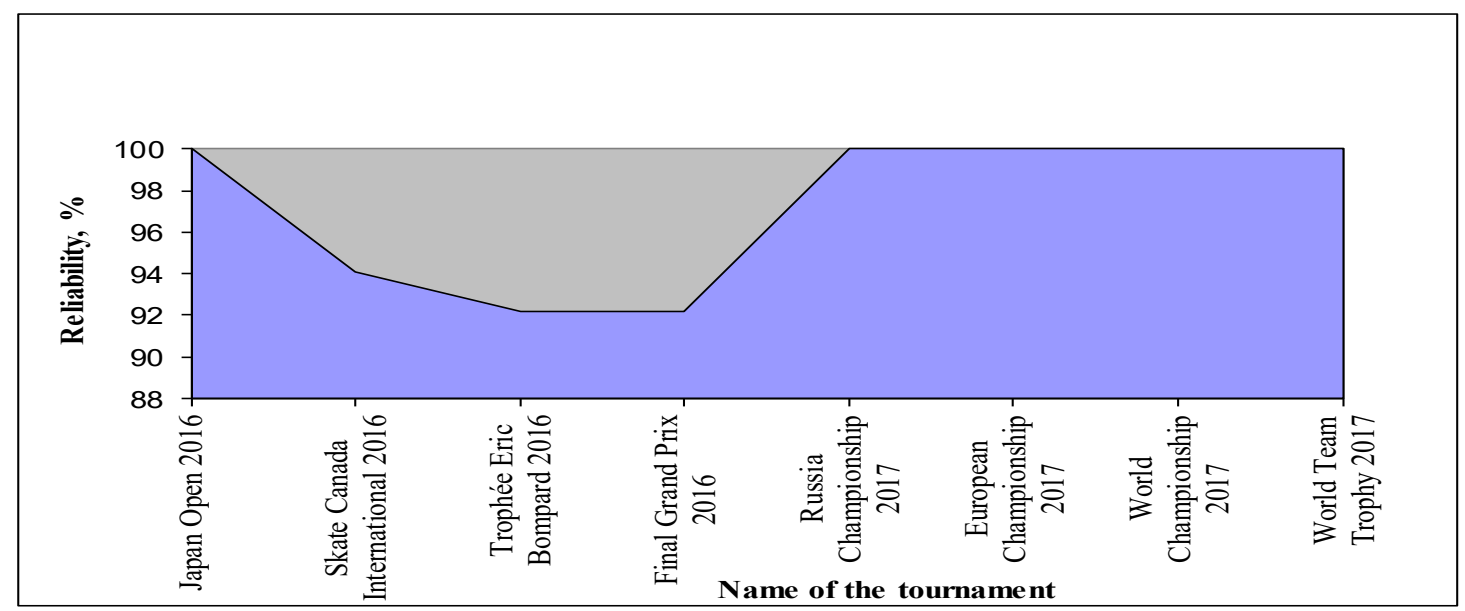

Figure 1 - Diagram of the reliability dynamics of E. Medvedeva's multi-turn jumps in the 2016-2017 season. 
Thus, the average reliability of the season leader is $97.30 \%$. Based on the presented results, we can conclude that E. Medvedeva practically did not make mistakes in jumps during the entire competition season.

Kaetlyn Osmond participated in seven tournaments

Table 3 - Calculation of the reliability of jumps' performance by K. Osmond at the tournaments of the season 2016-2017

\begin{tabular}{|c|c|c|c|}
\hline Tournament & Tperf., standard units & Tplan., standard units & N, \% \\
\hline Finlandia Trophy 2016 & 64 & 97 & 65,98 \\
\hline $\begin{array}{c}\text { Skate Canada } \\
\text { International 2016 }\end{array}$ & 74 & 100 & 84 \\
\hline Cup of China 2016 & 65 & 103 & 89 \\
\hline $\begin{array}{c}\text { Grand Prix of Figure } \\
\text { Skating Final 2016 }\end{array}$ & 89 & 103 & 78,64 \\
\hline $\begin{array}{c}\text { Canadian Championship } \\
\text { 2017 }\end{array}$ & 81 & 94 & 54,26 \\
\hline $\begin{array}{c}\text { Four Continents } \\
\text { Championships 2017 }\end{array}$ & 51 & 103 & 85,44 \\
\hline $\begin{array}{c}\text { World Championships } \\
\text { 2017 }\end{array}$ & 88 & & \\
\hline
\end{tabular}

Figure 2 in the form of a diagram shows the dynamics of reliability of execution of multi-turn jumps in the season 2016-2017 K. Osmond.

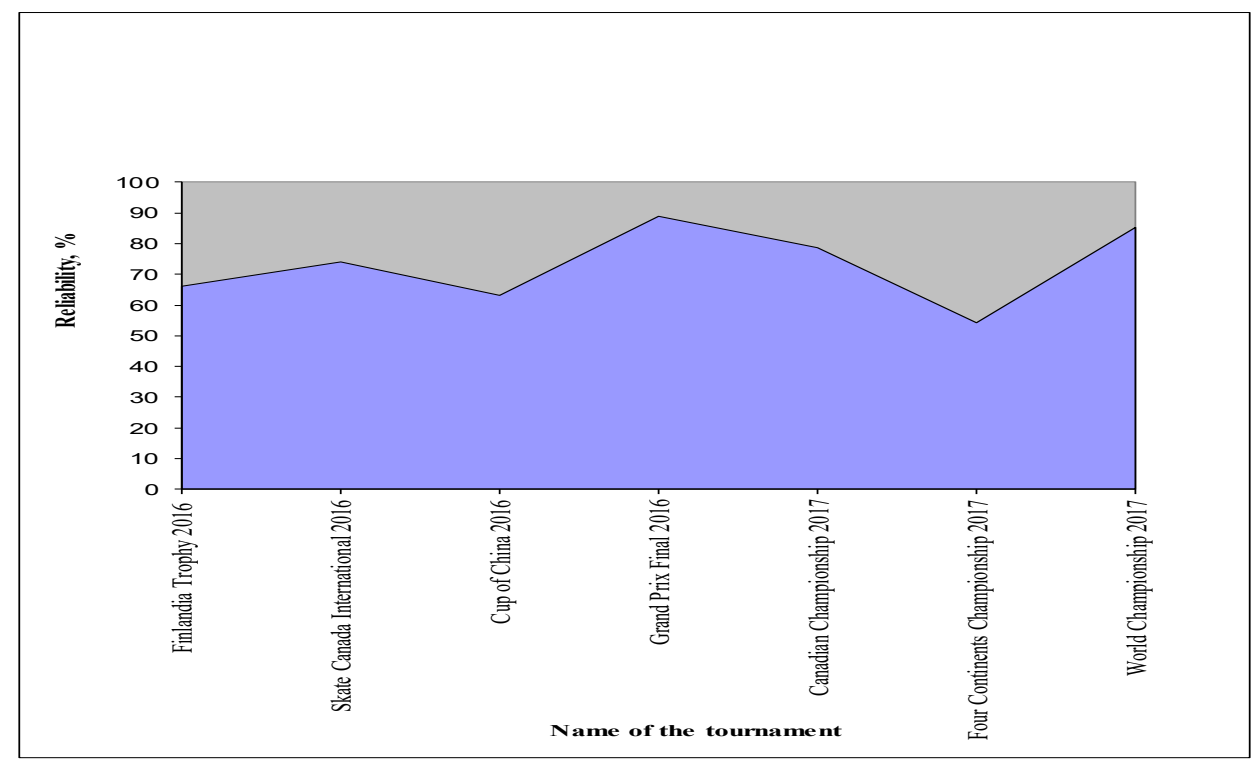

Figure 2-Diagram of the reliability dynamics of K. Osmond's multi-turn jumps in the 2016-2017 season.

The average reliability of K. Osmond's performances is $72.92 \%$. Table 3 show that $\mathrm{K}$. Osmond made mistakes in jumps at all the competitions. The largest number of significant shortcomings happened at Four Continents Championships, where half of her jumps in the program were performed poorly. At Grand Prix Final and World Championships K. Osmond performed quite successfully: the reliability of her jumps at these tournaments was the highest. As for during the 2016-2017 season: Finlandia Trophy 2016; Skate Canada International 2016; Cup of China 2016; Grand Prix of Figure Skating Final 2016; Canadian Championship 2017; Four Continents Championships 2017; World Championships 2017. 
Table 4 - Calculation of the jumps' performance reliability by G. Daleman at each tournament of the season 2016-2017

\begin{tabular}{|c|c|c|c|}
\hline Tournament & Tperf., standard units & Tplan., standard units & N, \% \\
\hline Nebelhorn Trophy 2016 & 55 & 94 & 58,51 \\
\hline Skate America 2016 & 71 & 102 & 69,61 \\
\hline $\begin{array}{c}\text { Trophée Eric Bompard } \\
\text { 2016 }\end{array}$ & 73 & 94 & 77,66 \\
\hline $\begin{array}{c}\text { Canadian Championship } \\
\text { 2017 }\end{array}$ & 81 & 101 & 80,20 \\
\hline $\begin{array}{c}\text { Four Continents } \\
\text { Championship 2017 }\end{array}$ & 79 & 101 & 78,22 \\
\hline $\begin{array}{c}\text { World Championship } \\
\text { 2017 }\end{array}$ & 95 & 101 & 94,06 \\
\hline $\begin{array}{c}\text { World Team Trophy } \\
2017\end{array}$ & 85 & 101 & 84,16 \\
\hline
\end{tabular}

Figure 3 in the form of a diagram shows the dynamics of the reliability of the execution of multi-turn jumps in the season 2016-2017 G. Daleman, which on average this skater reaches 77.49\%.

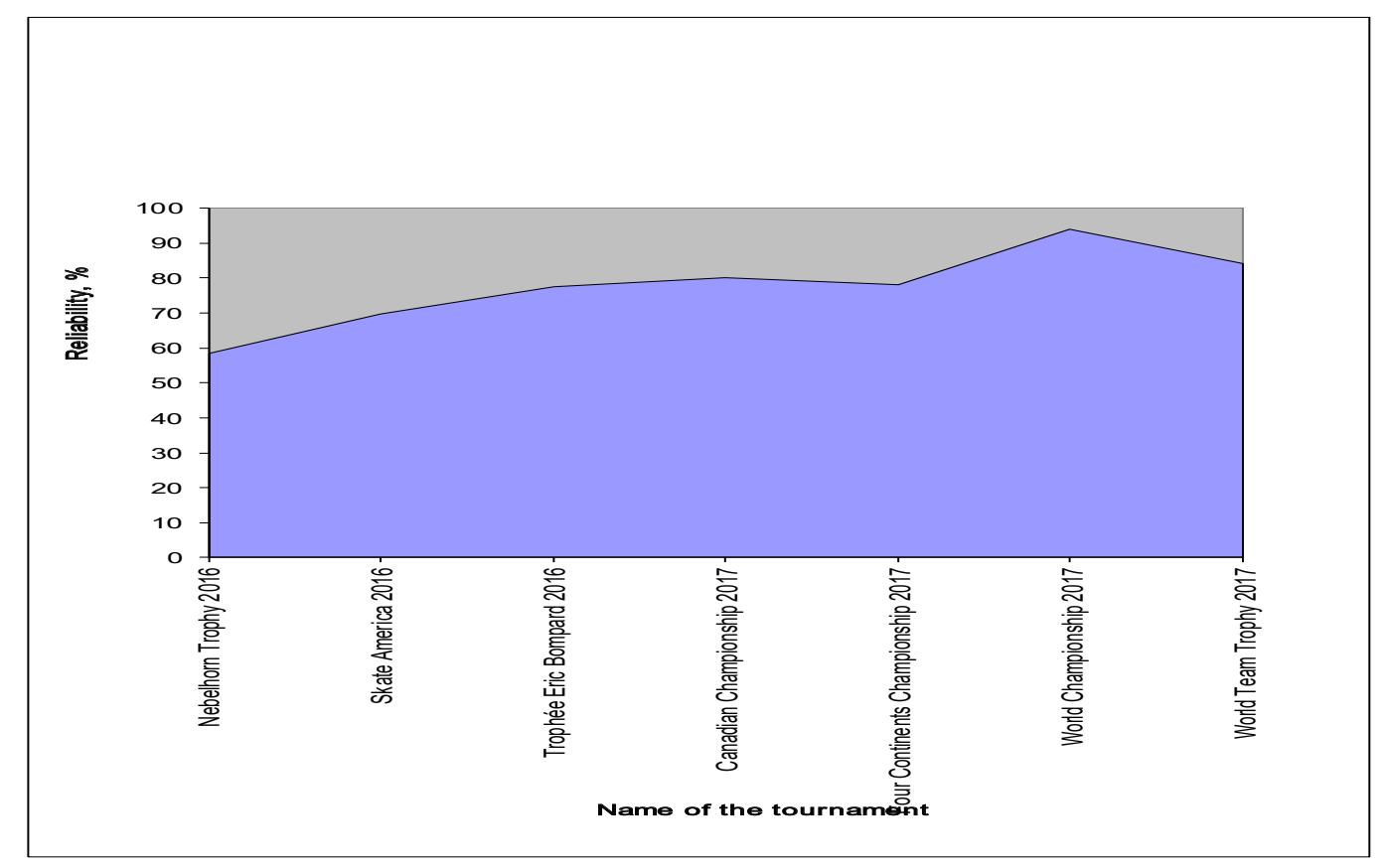

Figure 3-Diagram of reliability dynamics of G. Daleman multi-turn jumps in the 2016-2017 season

G. Daleman was gradually gaining her competition form during the season. With each tournament, the reliability of her jumps increased and at the most important competition (World Championships 2017) it reached the peak.

Table 5 shows the data on weight and height indicators of the female figure skaters who occupied the winners' podium at 2017 World Figure Skating Championships.

E. Medvedeva is the only participant who had a lack of body weight $(16-18,5 \mathrm{~kg} / \mathrm{m} 2)$. At that time, she was the youngest figure skater under 18 involved in the research, whose body had not yet fully passed the puberty. Nevertheless, the calculations showed that she had the greatest reliability of jumps. Since E. Medvedeva had the lowest Quetelet index, it leads to the conclusion that a big difference between height and weight can provide reliable jumps in the future.

Moreover, it should be noted that absolute values of height and weight do not affect the reliability of multi-turn jumps' performance. Only body mass index, showing the degree of fit between an individual's weight and height, affects the reliability of multi-turn jumps' performance. 
Table 5 - Calculation of the Quetelet Index for the study participants

\begin{tabular}{|c|c|c|c|c|}
\hline $\begin{array}{c}\text { Final standings } \\
\text { at 2017 World } \\
\text { Championships }\end{array}$ & Figure skater & Height, $\mathrm{m}$ & Weight, $\mathrm{kg}$ & $\begin{array}{c}\text { Quetelet Index, } \\
\mathrm{kg} / \mathrm{m} 2\end{array}$ \\
\hline 1 & $\begin{array}{c}\text { Evgenia } \\
\text { Medvedeva }\end{array}$ & 1,59 & 41 & 16,22 \\
\hline 2 & Kaetlyn Osmond & 1,65 & 52 & 19,10 \\
\hline 3 & Gabrielle Daleman & 1,55 & 46 & 19,15 \\
\hline
\end{tabular}

\section{CONCLUSION}

The reliability of multi-turn jumps' performance of the strongest representatives of women's single skating in the 2016-2017 season was high: over 60\% for all the participants, and for 2017 World champion Evgenia Medvedeva it was close to $100 \%$. After having analysed the diagrams showing the changes in reliability indicators at each tournament, we should note that either the figure skaters improved their jumps' performance from competition to competition with a peak at major tournaments (European Championships, World Championships, Four Continents Championships), or some athletes experienced a decrease in mid-season results, which is quite logical, because the whole training process during the competition season is structured in such a way as to achieve the maximum result at the main competitions.

To sum up, weight and height parameters influence the reliability of the multi-turn jumps performance (the lower the body mass index, the greater the reliability of multi-turn jumps' performance). In particular, according to the Chaddock scale, the strength of relationship between the indicators of body mass index and the reliability of multi-turn jumps' performance is significant $(-0,53)$. The highest reliability of jumps' performance in the season 2016-2017 is shown by the figure skater with the lowest body mass index (Evgenia Medvedeva has the average reliability in the season of $97,3 \%$, her BMI was $16,22 \mathrm{~kg} / \mathrm{m} 2$ ).

The results of the study prove that the leaders in women's single figure skating, who have the aim of achieving a high result, keep the difference between their height and weight quite large.

\section{REFERENCES}

1. Martynenko, I.V., Yarushin, S.A. Investigation of the functional condition of sportsmen during the adaptation to cyclic physical exercises. Sovremennye issledovaniya social'nyh problem: elektronnyj nauchnyj zhurnal. 2016; 7 (63): 34-46. (In Russ.).

2. Oreshkina, I.N., Bykov, E.V., Kolomeec, O.I., Martynenko, I.V. Monitoring of the training process of qualified speed skaters using the FIRSTBEAT technique. Problemy sovremennogo pedagogicheskogo obrazovaniya. Nauchnyj zhurnal. 2016; 53(7): 153-160. (In Russ.).

3. Tikhomirov, A. K., Skuratova, T. V., Tikhomirova, V. L. Konkobezhnyy sport. Ezhegodnik [Skating sport. Yearbook]. Moscow, Physical culture and sport. 1983: 79. (In Russ.).

4. Kiselev, Yu.Ya. On the preparations of weightlifters to unaccustomed conditions of activity in the competition. Teoriya i praktika fizicheskoy kultury $=$ Theory and Practice of Physical Culture. 1964; 7: 69-71. (In Russ., In Engl.).

5. Smirnov, Yu. I., Zulayev, I. I. Metody otsenki i kontrolya sorevnovatelnoy nadezhnosti sportsmen [Methods of evaluation and control of competitive reliability of an athlete]. Moscow, MGAFK. 1995: 79 (In Russ.).

6. International skating union special regulations \& technical rules single \& pair skating and ice dance. Adopted at 56th Ordinary Congress. June 2016: 147.

7. Andrey I. Pyanzin. The structure of speedstrength readiness of the qualified athletes, going in for different kinds of sport. Pedagogikopsihologicheskie I medico-biologicheskie problemy fizicheskoj kul'tury I sporta = The Russian Journal of Physical Education and Sport. 2019; 14(2): 7076. DOI: 10.14526/2070-4798-2019-14-1-81-88 (In Russ., In Engl.).

8. Khamoui A.V., Brown L.E., Coburn J.W., Judelson D.A., Uribe B.P., Nguyen D., ... Noffal G.J. Effect of potentiating exercise volume on vertical hump parameters in recreationally trained men. Journal of Strength and Conditioning Research. 2009; 23(5): 1465-1469. DOI: 10.1519/ JSC.obo13e3181a5bcdd.

9. McBride J.M., Nimphius S., Erickson T.M. The acute effects of heathy-load squats and loaded countermovement jumps on sprint performance. Journal of Strength and Conditioning Research. 2005; 19(4): 893-897.

10. McCann M.R., Flanagan S.P. The effects of exercise selection and rest interval on postactivation potentiation of vertical jump performance. Journal of Strength and Conditioning Research. 2010; 24(5): 1285-1291. DOI: 10.1519/JSC.obo13e3181d6867c.

11. Mitchell C.J., Sale D.G. Enhancement of jump performance after a 5 -RM squat is associated with 
postactivation potentiation. European Journal of Applied Physiology. 2011; 111(8): 1957-1963. DOI: 10.1007/s00421-010-1823-x.

\section{Submitted: 09.07.2019}

Author's information:

Ivan V. Martynenko - Candidate of Pedagogics, Associate Professor, Russian State University of Physical Education, Sport, Youth and Tourism, 105122, Russia, Moscow, Sirenevyj bulvar, House 4, e-mail: w0102w@yandex.ru

Ekaterina S. Borisenkova - Candidate of Pedagogics, Associate Professor, Ural State University of Physical Education, 454091, Russia, Chelyabinsk, Ordzhonikidze str., House 1, e-mail: ekboris24@mail.ru 